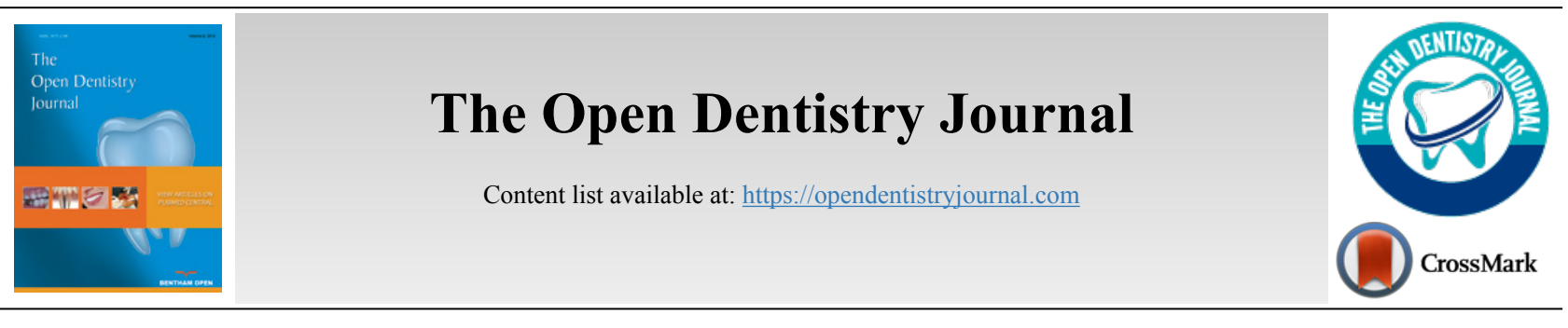

RESEARCH ARTICLE

\title{
Clinical and Biochemical Evaluation of the Effect of Diode Laser Treatment Compared to the Non-surgical and Surgical Treatment of Periodontal Diseases
}

\author{
Mirlinda Sopi ${ }^{1}$, Ferit Koçani ${ }^{2}$, Merita Bardhoshi ${ }^{3}$ and Kastriot Meqa ${ }^{4, *}$ \\ ${ }^{1}$ Dentistry School,University of Pristina, Pristina, Kosovo \\ ${ }^{2}$ Department of Dental Pathology and Endodontics, University of Pristina Dentistry School, Pristina, Kosovo \\ ${ }^{3}$ Department of Oro-Maxillofacial Surgery, Medical University of Tirana, Tirana, Albania \\ ${ }^{4}$ Department of Periodontology and Oral Medicine, University of Pristina Dentistry School, Pristina, Kosovo
}

\begin{abstract}
:
Background:

Periodontal therapy consists of eliminating the inflammation, treating periodontal pockets, motivating the patient for oral hygiene, and, if necessary, for surgical treatment. Recently, the application of a diode laser is widely being investigated for periodontal disease treatment.

Objective:

The analysis and evaluation of the clinical and biochemical impact of diode laser periodontal treatment, compared to either surgical or nonsurgical, therapy, was the aim of this study.

Methods:

The study involved 80 patients older than 18 with at least 20 teeth. Evaluation of periodontal parameters was done conveniently on a single-rooted tooth (incisive, canine, premolar) on six surfaces, before the start of periodontal therapy, and after three, and six months. The laser used in the study was a diode laser with a wavelength of $980 \mathrm{~nm}$. Digital X-rays were taken for bone level evaluation before and after the treatment. The presence of a bone destruction mediator (Matrix metalloproteinase-8 - MMP-8) was evaluated by the dipstick immunoassay test. Biochemical analysis and radiographic measurements were evaluated at the baseline and six months after the treatment. The statistical analysis included $\chi^{2}$-test and one-way ANOVA.

Results:

The results of this study showed that diode laser treatment was more effective in reducing periodontal clinical parameters, lowering MMP-8 levels and reducing the bone loss, compared to the group treated with scaling and root planning, or with a surgical approach.

Conclusion:

Diode laser may be considered as an effective alternative for periodontal treatment, with benefits in clinical and biochemical parameters.
\end{abstract}

Keywords: Periodontitis, Diode laser, Matrix metalloproteinase-8, Periodontal surgery, SRP, Bone-loss.

\begin{tabular}{|l|l|l|l|}
\hline Article History & Received: January 14, 2020 & Revised: April 21, 2020 & Accepted: April 27, 2020
\end{tabular}

\section{INTRODUCTION}

Periodontitis is a chronic disease with exudative, proliferative and degenerative inflammation of the toothsupporting apparatus. The etiological factor of the periodontal diseases is dental plaque. Dental plaque is diverse in microbial content, with direct action in the occurrence of periodontal

"Address correspondence to this author at the, Department of Periodontology and Oral Medicine, University of Pristina Dentistry School, Pristina, Kosovo;

Tel: +383 44310 761; E-mail: kastriot.meqa@uni-pr.edu diseases [1]. The disease is characterized by chronic progression with periods of remission. Clinical manifestation is presented by inflammation of the gingiva, formation of periodontal pockets, and destruction of the periodontal ligament and alveolar bone; with the disease progression and destruction of the supporting apparatus, the tooth is lost.

Periodontitis is characterized by loss of connective and bone tissue, initiated primarily by a group of enzymes called Matrix Metalloproteinases (MMPs), of which there are 22 
groups known so far, but Matrix Metaloproteinasis-8 (MMP-8) is responsible for the destruction of periodontal tissue. Functional disorders of the periodontium are in direct ratio to the destructive processes that result in complete functional disintegration of the periodontium and tooth loss [2 - 4].

Besides the conventional methods of diagnosing periodontitis, based on the clinical evaluation of signs and symptoms, the X-ray analysis is an auxiliary diagnostic method [5]. However, the clinical evaluation and X-ray analysis do not provide us with data about the cause of the periodontitis, the patient's predisposition to the disease, whether the disease is progressing, or whether we have a positive response to the therapy applied $[6,7]$. Therefore, when evaluating the patient's periodontal status, microbiological, immunological, and genetic tests should also be considered [8]. There are several biochemical methods used nowadays to determine MMP-8 in gingival exudate: immune-fluorometric assay (IFMA), Dipstick, dento-Analyzer, and ELISA. In the study, in which these methods were compared for the determination of MMP-8 in gingival exudate in periodontitis patients, the results showed that they are correlated with each other, except for the ELISA test [9]. Several clinical trials also demonstrate the correlation of periodontal clinical diagnostic parameters (periodontal pocket depth) with the presence of MMP-8 in the gingival exudate [10 - 12].

Research showed that, although SRP alone and SRP combined with surgical flap were effective treatment modalities for managing periodontitis [13 - 16], removal of subgingival bacterial deposits, calculus, and infected root cement are not always achieved by conventional mechanical debridement [17 - 22]. Researchers have proposed the use of lasers for periodontal treatment as an adjunct tool for reaching this goal. Recently, the application of diode laser is being investigated as an alternative modality for the treatment of periodontitis-involved sites [23 - 26]. The advantages of this method of treatment are bactericidal and haemostatic effect, good access to anatomically difficult areas, bio-stimulation, comfortable for patient treatment, and ease of handling [27 32].

The study aimed to analyze and evaluate the clinical and biochemical impact of diode laser in periodontal therapy, compared to either non-surgical or surgical treatment.

The working hypothesis suggested that periodontal therapy using diode laser would have better clinical and biochemical results, compared to surgical and non-surgical therapy.

On the other hand, the null hypothesis for this study predicted that clinical and biochemical parameters after periodontal therapy with diode laser would be similar to other treatment options used.

\section{MATERIALS AND METHODS}

The study involved a total of 80 patients over 18 years of age with at least 20 teeth present. Inclusion criteria were: periodontitis patients over 18 years of age, with 4-6 mm deep pockets in at least two sites, and communicative and cooperative patients, who gave their written informed consent to participate in the study. Exclusion criteria were: pregnant women, lactating women, patients using antibiotics for other reasons, patients with addictions, (such as smoking, and /or alcohol consumption), and acute or chronic systemic diseases.

\subsection{Ethical Approval}

This study was approved by the Ethical Board of the Medical Faculty of the University of Prishtina (Nr. 3833, date May $\left.12^{\text {th }}, 2017\right)$ and by the Ethical Committee of the Dental Chamber of Kosovo (Nr. 482/2018, dated December $6^{\text {th }}, 2018$ ), following the recommendations of the Declaration of Helsinki guiding medical doctors in biomedical research involving human subjects, adopted by the $18^{\text {th }}$ World Medical Assembly, Helsinki, Finland, June 1964 and as revised by the $29^{\text {th }}$ World Medical Assembly, Tokyo, Japan, October 1975.

\subsection{Study Groups}

Periodontal treatment, specific to the treatment group, was performed on the planed sections of the mouth, whereas evaluation and measurements of periodontal parameters were conveniently performed on a single-rooted tooth (incisive, canine, premolar) on six surfaces.

Patients were divided into three study groups:

Group I - Patients treated with basic therapy (removal of dental plaque and calculus) and scaling and root planning (SRP group). The standard non-surgical mechanical debridement of the periodontal pockets was performed in this group. For ethical reasons, patients of this group were treated surgically after the conclusion of the study, due to their pocket probing depths.

Group II - Patients treated with basic therapy and diode laser application (LT group). This group was treated with a diode laser (Laser $\mathrm{HF}^{\mathcal{O}}$, Hager-Werken, Germany), with each tooth, inside the periodontal pocket, exposed for one minute using the light of wavelength $980 \mathrm{~nm}$, and with $10 \mathrm{~mW}$ of power. During the exposure, the fiber of the laser was inserted in the pocket.

Group III - Patients treated with basic therapy, and surgical procedure with flap (ST group). The standard surgical procedure, with modified Widman's flap approach for the mechanical debridement of the periodontal pockets, was performed in this group.

\subsection{Periodontal Clinical Parameters}

The periodontal assessment was done using the following parameters: clinical attachment level (CAL), gingival recession (GR), pocket probing depth (PPD), Greene-Vermilion plaque index (PI), Loe-Sillnes gingival index (GI), and the tooth mobility index (TMI). These measurements were performed on six surfaces of the chosen single-rooted tooth using a periodontal probe. The assessment of the clinical parameters was performed in the same teeth, at the baseline and after the treatment, in three and six months, respectively.

\subsection{Evaluation of MMP-8 in the Gingival Exudate}

The presence of the bone destruction mediator (MMP-8) was assessed using the dipstick immunoassay test. This 
commercially available quick test (Hager-Werken, Germany) is based on an immunoassay sandwich using highly specific Moabit 8706 and 8708 Moabit monoclonal antibodies conjugated with latex particles. It is a quick, painless and accurate test, which helps to detect early periodontal destruction. The gingival crevicular fluid is taken from the sulcus with a collection strip, left in the sulcus for 30 seconds, then placed in a test tube containing a buffer and the result is read after five minutes. The evaluation of MMP- 8 was performed at the baseline and six months after the periodontal treatment.

\subsection{Bone-Loss Assessment Using Digital X-Ray}

$\mathrm{X}$-ray assessment was performed at the baseline and six months after the treatment, using digital panoramic images to quantify the amount of bone loss by digitally measuring bone levels on the mesial and distal sites of the examined teeth in each treated quadrant.

\subsection{Statistical Analysis}

Data processing was done with the SPSS Statistics version 22.0. The data obtained are presented in tables and graphs. No normality test was performed to assess data distribution. The structure index, arithmetic mean, standard deviation, mean standard error, and minimum and maximum values were calculated using the statistical parameters. The testing of CAL, GR and PPD values was performed using the $\chi^{2}$-test, One-Way ANOVA, and Tukey-Kramer Multiple Comparison Test.
Testing of PI, GI and TMI was done using the Kruskal-Wallis test, Dunn's Multiple Comparison Test. The difference is significant when $\mathrm{P}<0.05$.

\section{RESULTS}

The results of the study show that all three treatment methods have shown improvement when compared to initial pre-treatment values. However, diode laser treatment has shown to be more effective in reducing periodontal clinical parameters, such as CAL, PPD, GR, GI; and also lowered MMP-8 levels and reduced bone loss compared to the group treated with scaling and root planing. Whereas, compared to the group treated with laser surgery, it showed greater improvement of the clinical parameters PPD, CAL, GR, a decrease of MMP-8 levels and reduction of bone loss in X-ray evaluation. The difference between laser and SRP group three months after treatment was statistically significant only for CAL $(\mathrm{P}<0.0001), \mathrm{PPD}(\mathrm{P}<0.001)$ and $\mathrm{GI}(\mathrm{P}<0.001)$. The same difference was observed after six months, with CAL (P $<0.0001)$, PPD $(\mathrm{P}<0.001)$, GR $(\mathrm{P}<0.05)$, and GI $(\mathrm{P}<0.001)$ (Table 1).

The difference between surgical and SRP treatment three months after treatment was statistically significant only for the clinical attachment level $(\mathrm{P}<0.05)$ and the probing depth ( $\mathrm{P}$ $<0.001)$. The same difference applies after six months as well, with the clinical attachment level $(\mathrm{P}<0.05)$ and the probing depth $(\mathrm{P}<0.001)$, (Table 2).

Table 1. The comparison of periodontal clinical parameters of SRP group vs. Laser group at three and six months after the treatment.

\begin{tabular}{|c|c|c|c|c|}
\hline \multirow{2}{*}{$\begin{array}{c}\text { Periodontal Clinical Parameters } \\
-\end{array}$} & \multicolumn{2}{|c|}{ After 3 Months } & \multicolumn{2}{|c|}{ After 6 Months } \\
\hline & SRP & Laser & SRP & Laser \\
\hline Clinical attachment level & $3.47 \pm 0.45$ & $3.33 \pm 0.34$ & $3.38 \pm 0.38$ & $3.07 \pm 0.28$ \\
\hline$(\mathrm{mm} \pm \mathrm{SD})$ & $\mathrm{P}<0.0001$ & & $\mathrm{P}<0.0001$ & \\
\hline Periodontal pocket depth & $3.27 \pm 0.41$ & $3.13 \pm 0.31$ & $3.01 \pm 0.37$ & $2.79 \pm 0.29$ \\
\hline$(\mathrm{mm} \pm \mathrm{SD})$ & $\mathrm{P}<0.001$ & & $\mathrm{P}<0.001$ & \\
\hline Gingival recession & $0.42 \pm 0.18$ & $0.41 \pm 0.20$ & $0.49 \pm 0.17$ & $0.43 \pm 0.18$ \\
\hline$(\mathrm{mm} \pm \mathrm{SD})$ & $\mathrm{P}>0.05$ & & $\mathrm{P}<0.05$ & \\
\hline Gingival index & $0.38 \pm 0.12$ & $0.29 \pm 0.11$ & $0.14 \pm 0.08$ & $0.15 \pm 0.10$ \\
\hline$($ mean $\pm \mathrm{SD})$ & $\mathrm{P}<0.001$ & & $\mathrm{P}<0.01$ & \\
\hline Tooth mobility index & $0.86 \pm 0.25$ & $0.64 \pm 0.19$ & $0.77 \pm 0.17$ & $0.58 \pm 0.13$ \\
\hline$($ mean \pm SD $)$ & $\mathrm{P}>0.05$ & & $\mathrm{P}>0.05$ & \\
\hline Plaque index & $0.35 \pm 0.10$ & $0.39 \pm 0.11$ & $0.38 \pm 0.12$ & $0.40 \pm 0.20$ \\
\hline$($ mean \pm SD $)$ & $\mathrm{P}>0.05$ & & $\mathrm{P}>0.05$ & \\
\hline
\end{tabular}

Table 2. The comparison of periodontal clinical parameters of SRP group vs. surgical group at three and six months after the treatment.

\begin{tabular}{|c|c|c|c|c|}
\hline Periodontal clinical parameters & \multicolumn{2}{|c|}{ After 3 Months } & \multicolumn{2}{c|}{ After 6 Months } \\
\hline- & SRP & Surgery & SRP & Surgery \\
\hline Clinical attachment level & $3.47 \pm 0.45$ & $3.33 \pm 0.34$ & $3.38 \pm 0.38$ & $3.31 \pm 0.33$ \\
\hline$(\mathrm{mm} \pm \mathrm{SD})$ & $\mathrm{P}<0.05$ & & $\mathrm{P}<0.01$ & \\
\hline Periodontal pocket depth & $3.27 \pm 0.41$ & $3.13 \pm 0.31$ & $3.01 \pm 0.37$ & $2.94 \pm 0.30$ \\
\hline$(\mathrm{mm} \pm \mathrm{SD})$ & $\mathrm{P}<0.001$ & & $\mathrm{P}<0.001$ & \\
\hline
\end{tabular}


(Table 2) cont.....

\begin{tabular}{|c|c|c|c|}
\hline Periodontal clinical parameters & \multicolumn{2}{|c|}{ After 3 Months } & \multicolumn{2}{|c|}{ After 6 Months } \\
\hline- & SRP & Surgery & SRP \\
\hline Gingival recession & $0.42 \pm 0.18$ & $0.39 \pm 0.18$ & $0.49 \pm 0.17$ \\
\hline (mm \pm SD) & $\mathrm{P}>0.05$ & & $\mathrm{P}>0.05$ \\
\hline Gingival index & $0.38 \pm 0.12$ & $0.29 \pm 0.11$ & $0.14 \pm 0.08$ \\
\hline (mean \pm SD) & $\mathrm{P}>0.05$ & & $\mathrm{P}>0.05$ \\
\hline Tooth mobility index & $0.86 \pm 0.25$ & $0.64 \pm 0.20$ & $0.77 \pm 0.17$ \\
\hline (mean \pm SD) & $\mathrm{P}>0.05$ & & $0.66 \pm 0.20$ \\
\hline Plaque index & $0.35 \pm 0.10$ & $0.39 \pm 0.12$ & $\mathrm{P}>0.05$ \\
\hline (mean \pm SD) & $\mathrm{P}>0.05$ & & $0.38 \pm 0.12$ \\
\hline
\end{tabular}

Table 3. The comparison of periodontal clinical parameters of Surgical group vs. Laser group at three and six months after the treatment.

\begin{tabular}{|c|c|c|c|}
\hline Periodontal clinical parameters & \multicolumn{2}{|c|}{ After 3 Months } & \multicolumn{2}{|c|}{ Laser } \\
\hline- & Laser & Surgery & $3.07 \pm 0.28$ \\
\hline Clinical attachment level & $3.33 \pm 0.34$ & $3.33 \pm 0.34$ & $3.31 \pm 0.33$ \\
\hline (mm \pm SD) & $\mathrm{P}>0.05$ & & $\mathrm{P}<0.05$ \\
\hline Periodontal pocket depth & $3.13 \pm 0.31$ & $3.13 \pm 0.31$ & $2.79 \pm 0.29$ \\
\hline (mm \pm SD) & $\mathrm{P}>0.5$ & $\mathrm{P}>0.05$ & $0.43 \pm 0.18$ \\
\hline Gingival recession & $0.41 \pm 0.20$ & $0.39 \pm 0.18$ & $\mathrm{P}<0.001$ \\
\hline (mm \pm SD) & $\mathrm{P}<0.01$ & & $0.42 \pm 0.17$ \\
\hline Gingival index & $0.29 \pm 0.11$ & $0.29 \pm 0.11$ & $\mathrm{P}>0.05$ \\
\hline (mean \pm SD) & $\mathrm{P}>0.05$ & & $0.15 \pm 0.10$ \\
\hline Tooth mobility index & $0.64 \pm 0.19$ & $0.64 \pm 0.20$ & $0.58 \pm 0.13$ \\
\hline (mean \pm SD) & $\mathrm{P}>0.05$ & & $\mathrm{P}>0.05$ \\
\hline Plaque index & $0.39 \pm 0.11$ & $0.39 \pm 0.12$ & $0.40 \pm 0.20$ \\
\hline (mean \pm SD) & $\mathrm{P}>0.05$ & $0.41 \pm 0.12$ \\
\hline
\end{tabular}

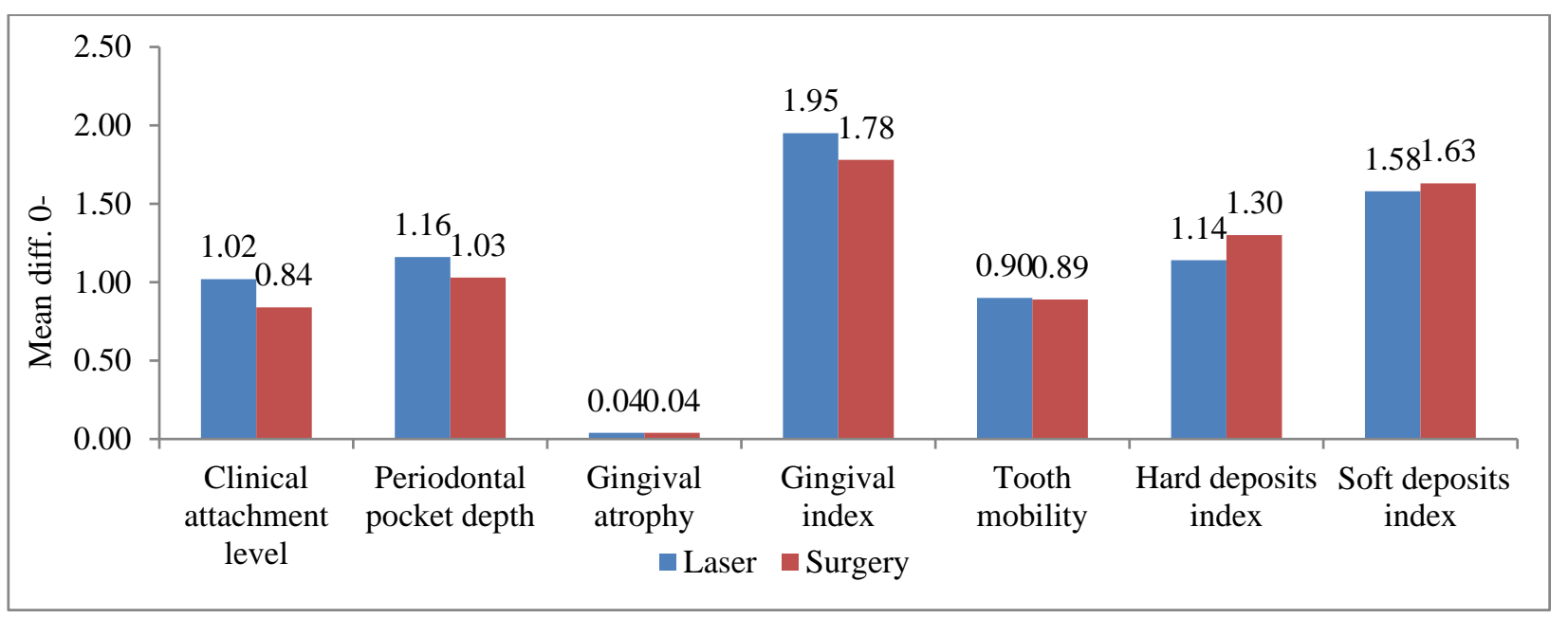

Fig. (1). The comparison of periodontal clinical parameters of Surgical vs. Laser treatment after three and six months.

The difference between surgical and laser treatment three months after treatment was statistically significant only for GR $(\mathrm{P}<0.01)$, and after 6 months for CAL $(\mathrm{P}<0.05)$ and $\mathrm{GR}$ $(\mathrm{P}<0.001)$, (Table 3).

Fig. (1) shows a significant improvement of all periodontal clinical parameters in laser-treated cases compared to surgical ones, with the PD and GR values being the most statistically significant.

The results of Matrix metalloproteinase- 8 test in the gingival exudate six months after the treatment were negative in $96.3 \%$ of the laser group, $86.3 \%$ of surgical-treated and $75.0 \%$ of SRP cases, and difference of statistical significance 
between the groups was $\mathrm{P}<0.001$ Fig. (2).

The mean values of the difference in bone loss reduction before treatment up to six months after treatment between the treatment groups, as shown in Fig. (3), had a statistically significant difference between the group treated with SRP and laser $(\mathrm{P}<0.05)$, and between the group treated with laser and surgery $(\mathrm{P}<0.05)$, while there was no significant difference found between the group treated with SRP and surgery $(\mathrm{P}<0.05)$.

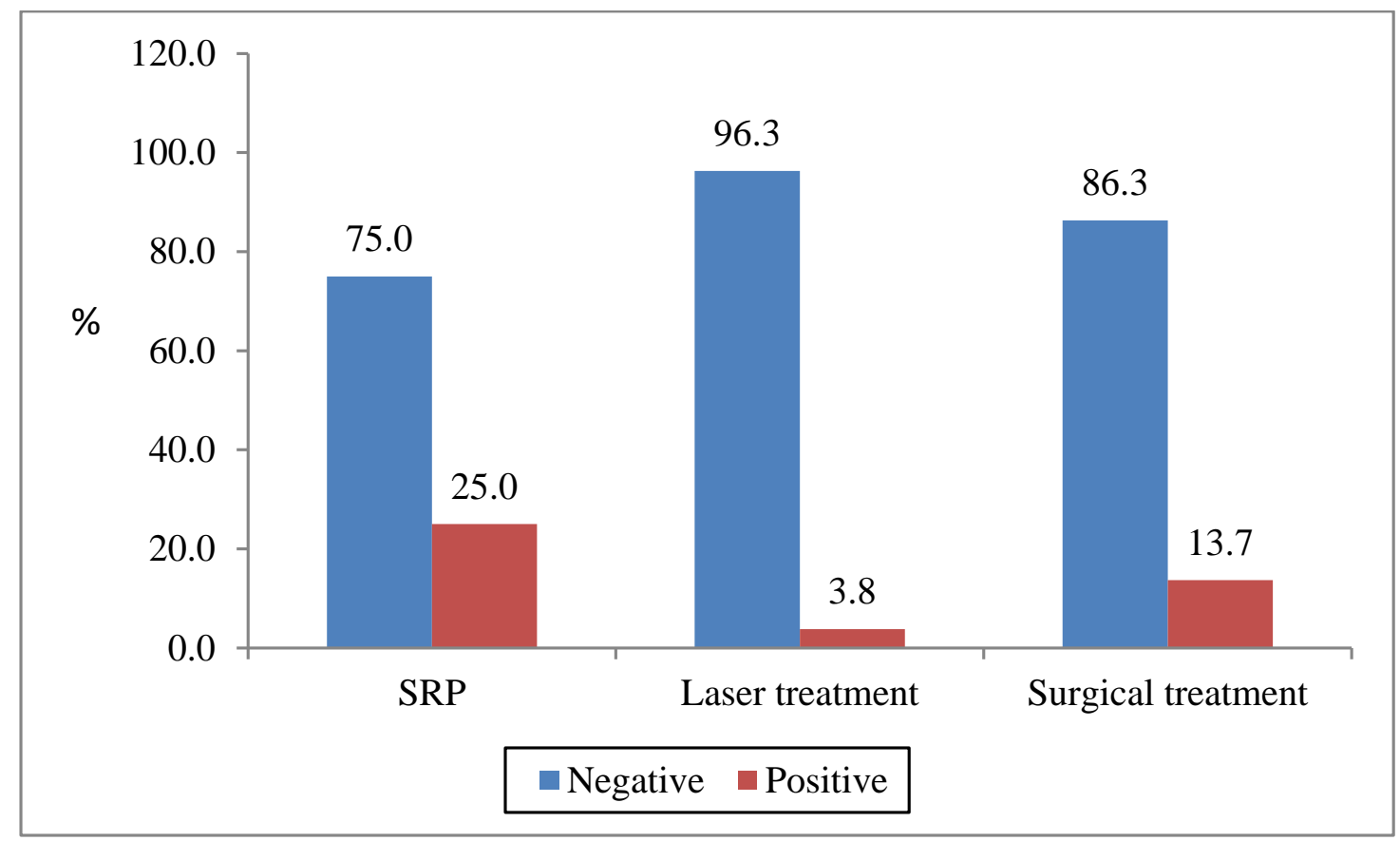

Fig. (2). The comparison of Matrix metalloproteinase- 8 in gingival exudate before and after treatment for each group.

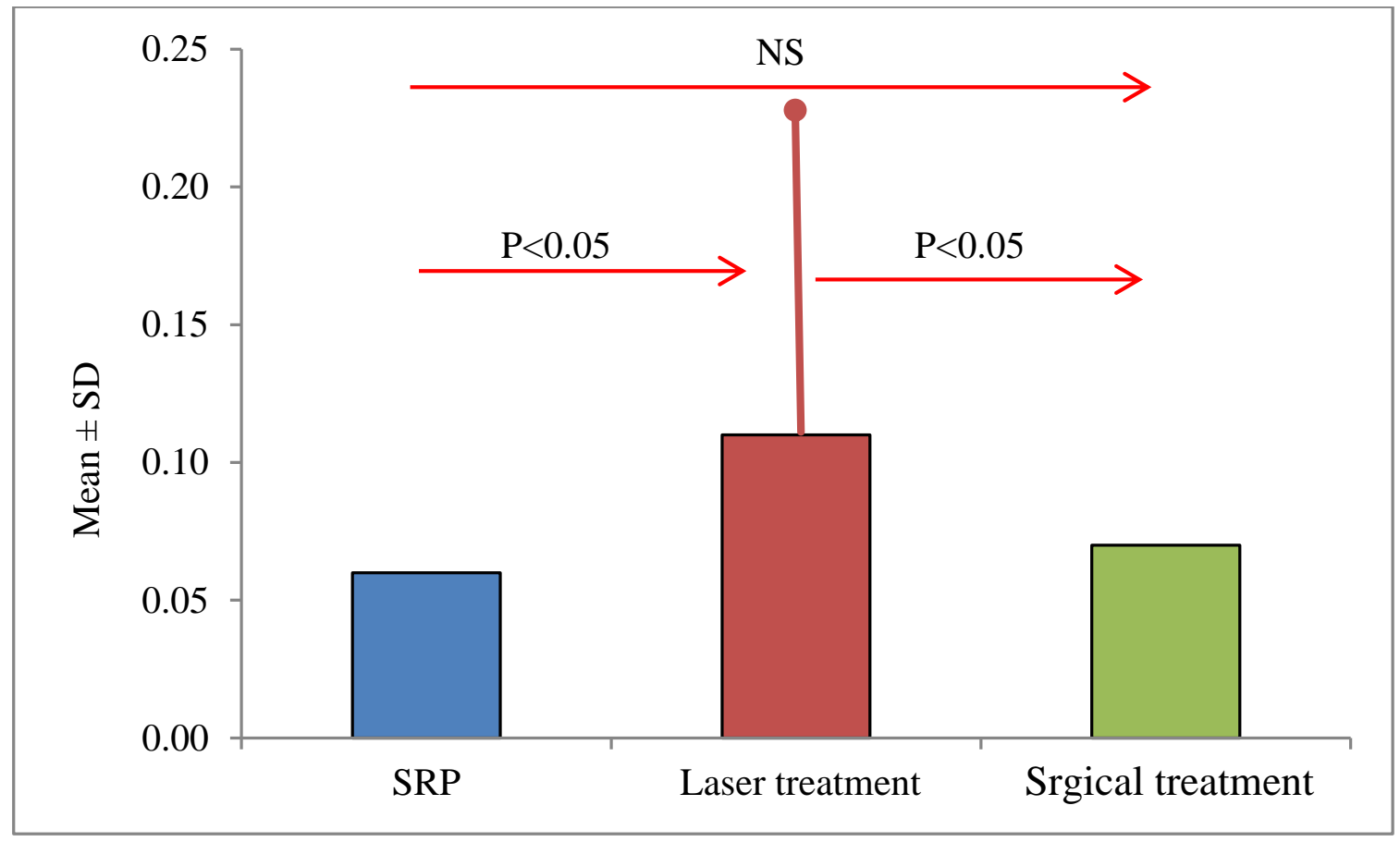

Fig. (3). Bone loss assessment through digital X-ray after treatment. 


\section{DISCUSSION}

This study aimed to analyze and evaluate the clinical and biochemical impact of diode laser on periodontal therapy, compared to surgical treatment and SRP. The results of our study are relatively encouraging for the use of laser in clinical practice. All clinical parameters analyzed showed clinical improvement three and six months after the laser treatment compared with patients who were treated with SRP and surgery, but of statistical significance were especially PD, CAL, GR, and GI. The methodology chosen for this study is designed to be comparable to most of the studies conducted for the same purpose. The decision to evaluate MMP-8 at the baseline and six months, but not three months, after the treatment was based on the time needed for a recovery to occur at the tested sites. Similar studies carried by other authors have shown different results of these treatment options, rising the questions if the benefits of laser treatment can shift the treatment of periodontitis to a non-surgical approach suitable for clinicians, as well as for patients. Qadri et al. (2005) achieved a reduction in clinical parameters, such as pocket depth, plaque, and gingival indices, more on the laser than on the placebo side $(\mathrm{p}<0.01)$. The total amount of MMP-8 increased in the placebo side, while it was lower on the laser side $(p=0.052)$ [33]. Improvement periodontal of clinical parameters $\mathrm{PD}, \mathrm{CAL}, \mathrm{GI}$, in patients treated with diode laser were found in a study of Caruso et al. [34], compared to conventional periodontal therapy. Edward et al. (2012) found that overall, $80 \%$ of pockets treated using diode laser restored a healthy $3 \mathrm{~mm}$ pocket depth [35]. On the other hand, Gokhale et al. (2012) found in their study no improvement in any periodontal clinical parameters in patients treated with laser compared to those treated with surgery [36]. Another study showed improvements only in the pocket depth parameter in laser-treated patients compared to patients treated with scaling and root planning, while no significant difference was observed in other parameters [37]. Saglam et al. Achieved significant improvements in clinical parameters and a decrease in MMP 8 levels in laser-treated patients [38]. Crispino et al. (2015) evaluated the effect of diode laser compared to the standard SRP and obtained encouraging results for the use of laser in clinical practice [39]. In the light of different attitudes of the authors regarding the laser therapy, even though there might be statistically better results for a certain novel modality of treatment, clinical implications of such results are hardly drawn from studies, like ours, and implemented routinely. The dental professionals should be free in their judgement of choosing the most suitable option for periodontal treatment.

\section{CONCLUSION}

Based on the results of our study, periodontal treatment using diode laser has shown better clinical, biochemical and Xray results compared to surgical and non-surgical treatments. The results could encourage clinicians to use a diode laser in the future protocols of non-surgical periodontal therapy. However, future randomized clinical studies are needed to demonstrate the long-term benefits of this non-surgical treatment option for periodontal diseases.

\section{AUTHORS' CONTRIBUTIONS}

Conceptualization, M.S. and F.K, methodology, M.S. and K.M, software, M.S, validation, M.S., F.K., and M.B, formal analysis, F.K, investigation, M.S, resources, M.S, data curation, M.S, writing-original draft preparation, M.S, writingreview and editing, M.S. and K.M, visualization, M.S, supervision, F.K. and M.B, project administration, M.S, funding acquisition, M.S. All authors have read and agreed to the published version of the manuscript.

\section{ETHICS APPROVAL AND CONSENT TO PARTICIPATE}

This study was approved by the Ethical Board of the Medical Faculty of the University of Pristina, Kosovo (No. 3833, date May 12th, 2017) and by the Ethical Committee of the Dental Chamber of Kosovo (No. 482/2018, dated December 6th, 2018),

\section{HUMAN AND ANIMAL RIGHTS}

No animals were used in this research. All human research procedures followed were in accordance with the ethical standards of the committee responsible for human experimentation (institutional and national), and with the Helsinki Declaration of 1975, as revised in 2013.

\section{CONSENT FOR PUBLICATION}

Written informed consent was obtained from each participant prior to the study.

\section{AVAILABILITY OF DATA AND MATERIALS}

The data of the materials mentioned in this study is available at Hager-Werken website (https://www.hagerwerken.de/en/katalog/dentist/devices_equip ment/laserhf-en/laserhf-comfort-2/).

\section{FUNDING}

None.

\section{CONFLICT OF INTEREST}

The authors declare no conflict of interest, financial or otherwise.

\section{ACKNOWLEDGEMENTS}

Declared none.

\section{REFERENCES}

[1] Darveau RP, Tanner A, Page RC. The microbial challenge in periodontitis. Periodontol 2000 1997; 14: 12-32. [http://dx.doi.org/10.1111/j.1600-0757.1997.tb00190.x] [PMID: 9567964]

[2] De Souza AP, Da Silva RA, Da Silva MAD, Catanzaro-Guimarães SA, Line SRP. Matrix metalloproteinases: The most important pathway involved with periodontal destruction. Braz J Oral Sci 2005; 4: 884-90.

[http://dx.doi.org/10.20396/bjos.v4i15.8641850]

[3] Sorsa T, Tjäderhane L, Salo T. Matrix metalloproteinases (MMPs) in oral diseases. Oral Dis 2004; 10(6): 311-8. 
[http://dx.doi.org/10.1111/j.1601-0825.2004.01038.x]

[PMID: 15533204]

[4] Gonçalves PF, Huang H, McAninley S, et al. Periodontal treatment reduces matrix metalloproteinase levels in localized aggressive periodontitis. J Periodontol 2013; 84(12): 1801-8.

[http://dx.doi.org/10.1902/jop.2013.130002] [PMID: 23537121]

[5] Rathnayake N, Akerman S, Klinge B, et al. Salivary biomarkers of oral health: A cross-sectional study. J Clin Periodontol 2013; 40(2): 140-7.

[http://dx.doi.org/10.1111/jcpe.12038] [PMID: 23174014]

[6] Syndergaard B, Al-Sabbagh M, Kryscio RJ, et al. Salivary biomarkers associated with gingivitis and response to therapy. J Periodontol 2014; 85(8): e295-303

[http://dx.doi.org/10.1902/jop.2014.130696] [PMID: 24502627]

[7] Leppilahti JM, Hernández-Ríos PA, Gamonal JA, et al. Matrix metalloproteinases and myeloperoxidase in GCF provide site-specific diagnostic value for chronic periodontitis. J Clin Periodontol 2014; 41: 348-56.

[http://dx.doi.org/10.1111/jcpe.12223] [PMID: 24382144]

[8] Ebersole JL, Nagarajan R, Akers D, Miller CS. Targeted salivary biomarkers for discrimination of periodontal health and disease(s). Front Cel Infec Microbio 2015; 5: 62

[http://dx.doi.org/10.3389\%2Ffcimb.2015.00062]

[9] Highfield J. Diagnosis and classification of periodontal disease. Aust Dent J 2009; 54(Suppl. 1): S11-26.

[http://dx.doi.org/10.1111/j.1834-7819.2009.01140.x] [PMID: 19737262]

[10] Geetha V, Vijay R. Radiology in Periodontics. J Ind Acad Oral Med Radiol 2013; 25: 24-9.

[http://dx.doi.org/10.5005/jp-journals-10011-1334]

[11] Kraft-Neumärker M, Lorenz K, Koch R, et al. Full-mouth profile of active MMP-8 in periodontitis patients. J Periodontal Res 2012; 47(1): $121-8$.

[http://dx.doi.org/10.1111/j.1600-0765.2011.01416.x] [PMID: 21958332]

[12] Sorsa T, Hernández M, Leppilahti J, Munjal S, Netuschil L, Mäntylä P. Detection of GCF MMP-8 levels with different laboratory and chair-side methods. Oral Dis 2010; 16: 39-45.

[http://dx.doi.org/10.1111/j.1601-0825.2009.01603.x] [PMID: 19627514]

[13] Izadi Borujeni S, Mayer M, Eickholz P. Activated matrix metalloproteinase- 8 in saliva as diagnostic test for periodontal disease? A case-control study. Med Microbiol Immunol (Berl) 2015; 204(6): $665-72$.

[http://dx.doi.org/10.1007/s00430-015-0413-2] [PMID: 25841875]

[14] Heikkinen AM, Nwhator SO, Rathnayake N, Mäntylä P, Vatanen P, Sorsa T. Pilot study on oral health status as assessed by an active matrix metalloproteinase- 8 chairside mouth rinse test in adolescents. J Periodontol 2016; 87(1): 36-40.

[http://dx.doi.org/10.1902/jop.2015.150377] [PMID: 26430926]

[15] Baeza M, Garrido M, Hernández-Ríos P, et al. Diagnostic accuracy for apical and chronic periodontitis biomarkers in gingival crevicular fluid: An exploratory study. J Clin Periodontol 2016; 43(1): 34-45. [http://dx.doi.org/10.1111/jcpe.12479] [PMID: 26556177]

[16] Al-Majid A, Alassiri S, Rathnayake N, Tervahartiala T, Gieselmann DR, Sorsa T. Matrix Metalloproteinase- 8 as an Inflammatory and Prevention Biomarker in Periodontal and Peri-Implant Diseases. Internat J Dent 2018.

[http://dx.doi.org/10.1111/jcpe.12259]

[17] Aimetti M. Nonsurgical periodontal treatment. Int J Esthet Dent 2014; 9(2): 251-67.

[PMID: 24765632]

[18] Kim TS, Schenk A, Lungeanu D, Reitmeir P, Eickholz P. Nonsurgical and surgical periodontal therapy in single-rooted teeth. Clin Oral Investig 2007; 11(4): 391-9. [http://dx.doi.org/10.1007/s00784-007-0144-x] [PMID: 17690922]

[19] Aljateeli M, Koticha T, Bashutski J, et al. Surgical periodontal therapy with and without initial scaling and root planing in the management of chronic periodontitis: A randomized clinical trial. J Clin Periodontol 2014; 41(7): 693-700.

[http://dx.doi.org/10.1111/jcpe.12259] [PMID: 24730621]

[20] Moritz A, Schoop U, Goharkhay K, et al. Treatment of periodontal pockets with a diode laser. Lasers Surg Med 1998; 22(5): 302-11. [http://dx.doi.org/10.1002/(SICI)1096-9101(1998)22:5<302::AID-LS M7>3.0.CO;2-T] [PMID: 9671997]

[21] Slot DE, Jorritsma KH, Cobb CM, Van der Weijden FA. The effect of the thermal diode laser (wavelength $808-980 \mathrm{~nm}$ ) in non-surgical periodontal therapy: A systematic review and meta-analysis. J Clin Periodontol 2014; 41(7): 681-92.

[http://dx.doi.org/10.1111/jcpe.12233] [PMID: 24460795]

[22] Aena PJ, Parul A, Siddharth P, Pravesh G, Vikas D, Vandita A. The clinical efficacy of laser assisted modified Widman flap: A randomized split mouth clinical trial. Indian J Dent Res 2015; 26(4): 384-9.

[http://dx.doi.org/10.4103/0970-9290.167626] [PMID: 26481885]

[23] Kamma JJ, Vasdekis VG, Romanos GE. The effect of diode laser (980 $\mathrm{nm}$ ) treatment on aggressive periodontitis: evaluation of microbial and clinical parameters. Photomed Laser Surg 2009; 27(1): 11-9. [http://dx.doi.org/10.1089/pho.2007.2233] [PMID: 19196111]

[24] Angelov N, Pesevska S, Nakova M, et al. Periodontal treatment with a low-level diode laser: Clinical findings. Gen Dent 2009; 57(5): 510-3. [PMID: 19903643]

[25] Passanezi E, Damante CA, de Rezende ML, Greghi SL. Lasers in periodontal therapy. Periodontol 2000 2015; 67(1): 268-91. [http://dx.doi.org/10.1111/prd.12067] [PMID: 25494605]

[26] De Micheli G, de Andrade AK, Alves VT, Seto M, Pannuti CM, Cai S. Efficacy of high intensity diode laser as an adjunct to non-surgical periodontal treatment: A randomized controlled trial. Lasers Med Sci 2011; 26(1): 43-8.

[http://dx.doi.org/10.1007/s10103-009-0753-5] [PMID: 20131073]

[27] Ejiri K, Aoki A, Yamaguchi Y, Ohshima M, Izumi Y. High-frequency low-level diode laser irradiation promotes proliferation and migration of primary cultured human gingival epithelial cells. Lasers Med Sci 2014; 29(4): 1339-47.

[http://dx.doi.org/10.1007/s10103-013-1292-7] [PMID: 23515630]

[28] Fujimura T, Mitani A, Fukuda M, et al. Irradiation with a low-level diode laser induces the developmental endothelial locus- 1 gene and reduces proinflammatory cytokines in epithelial cells. Lasers Med Sci 2014; 29(3): 987-94.

[http://dx.doi.org/10.1007/s10103-013-1439-6] [PMID: 24197516]

[29] Soares DM, Ginani F, Henriques AG, Barboza CA. Effects of laser therapy on the proliferation of human periodontal ligament stem cells. Lasers Med Sci 2015; 30(3): 1171-4.

[http://dx.doi.org/10.1007/s10103-013-1436-9] [PMID: 24013624]

[30] Castro GL, Gallas M, Núñez IR, Borrajo JL, Varela LG. Histological evaluation of the use of diode laser as an adjunct to traditional periodontal treatment. Photomed Laser Surg 2006; 24(1): 64-8. [http://dx.doi.org/10.1089/pho.2006.24.64] [PMID: 16503791]

[31] Yadwad KJ, Veena HR, Patil SR, Shivaprasad BM. Diode laser therapy in the management of chronic periodontitis - A clinicomicrobiological study. Interv Med Appl Sci 2017; 9(4): 191-8. [http://dx.doi.org/10.1556/1646.9.2017.38] [PMID: 29951284]

[32] Harris DM, Yessik M. Therapeutic ratio quantifies laser antisepsis: Ablation of Porphyromonas gingivalis with dental lasers. Lasers Surg Med 2004; 35(3): 206-13.

[http://dx.doi.org/10.1002/lsm.20086] [PMID: 15389740]

[33] Qadri T, Javed F, Johannsen G, Gustafsson A. Role of diode lasers $(800-980 \mathrm{~nm})$ as adjuncts to scaling and root planing in the treatment of chronic periodontitis: A systematic review. Photomed Laser Surg 2015; 33(11): 568-75.

[http://dx.doi.org/10.1089/pho.2015.3914] [PMID: 26436596]

[34] Caruso U, Nastri L, Piccolomini R, d'Ercole S, Mazza C, Guida L. Use of diode laser $980 \mathrm{~nm}$ as adjunctive therapy in the treatment of chronic periodontitis. A randomized controlled clinical trial. New Microbiol 2008; 31(4): 513-8.

[PMID: 19123307]

[35] Kusek ER, Kusek AJ, Kusek EA. Five-year retrospective study of laser-assisted periodontal therapy. Gen Dent 2012; 60(6): 540-3. [PMID: 23220310]

[36] Gokhale SR, Padhye AM, Byakod G, Jain SA, Padbidri V, Shivaswamy S. A comparative evaluation of the efficacy of diode laser as an adjunct to mechanical debridement versus conventional mechanical debridement in periodontal flap surgery: A clinical and microbiological study. Photomed Laser Surg 2012; 30(10): 598-603. [http://dx.doi.org/10.1089/pho.2012.3252] [PMID: 22889285]

[37] Dukić W, Bago I, Aurer A, Roguljić M. Clinical effectiveness of diode laser therapy as an adjunct to non-surgical periodontal treatment: A randomized clinical study. J Periodontol 2013; 84(8): 1111-7. [http://dx.doi.org/10.1902/jop.2012.110708] [PMID: 23075433]

[38] Saglam M, Kantarci A, Dundar N, Hakki SS. Clinical and biochemical effects of diode laser as an adjunct to nonsurgical treatment of chronic periodontitis: A randomized, controlled clinical trial. Lasers Med Sci 2014; 29(1): 37-46. [http://dx.doi.org/10.1007/s10103-012-1230-0] [PMID: 23161345] 
[39] Crispino A, Figliuzzi MM, Iovane C, et al. Effectiveness of a diode laser in addition to non-surgical periodontal therapy: Study of intervention. Ann Stomatol (Roma) 2015; 6(1): 15-20. [http://dx.doi.org/10.11138/ads/2015.6.1.015] [PMID: 26161248]

\section{(C) 2020 Sopi et al.}

This is an open access article distributed under the terms of the Creative Commons Attribution 4.0 International Public License (CC-BY 4.0), a copy of which is available at: (https://creativecommons.org/licenses/by/4.0/legalcode). This license permits unrestricted use, distribution, and reproduction in any medium, provided the original author and source are credited. 